\title{
Serum Glutathione Levels in Oral Leukoplakia and Oral Squamous Cell Carcinoma- A Clinicopathological Study
}

\author{
Shishir Ram Shetty ${ }^{1, *}$, Subhas Babu ${ }^{1}$, Suchetha Kumari ${ }^{2}$, Pushparaja Shetty ${ }^{3}$, Vijay $\mathbf{R}^{4}$, Arvind Karikal ${ }^{1}$ \\ ${ }^{1}$ Department of Oral Medicine and Radiology, AB Shetty memorial Institute of Dental Science, Nitte University, Mangalore, India \\ ${ }^{2}$ Department of Biochemistry, KS Hegde Medical Academy, Nitte University, Mangalore, India \\ ${ }^{3}$ Department of Oral Pathology, AB Shetty memorial Institute of Dental Science, Nitte University, Mangalore, India \\ ${ }^{4}$ Central research laboratory, Nitte University, Mangalore, India \\ *Corresponding author: drshishirshettyomr@yahoo.com
}

Received December 30, 2013; Revised February 01, 2013; Accepted February 25, 2013

\begin{abstract}
Oral cancer accounts for the majority of the cancer in South East Asian region and especially in the Indian subcontinent. If diagnosed at an early stage the disease is reported to have a better prognosis. Recently studies have been conducted to determine the levels of serum antioxidants for risk assessment of oral cancer. The aim of this study was to estimate the levels of glutathione in serum of patients with oral cancer, oral leukoplakia and healthy controls. Three study groups comprising of, 25 oral cancer patients, 25 oral leukoplakia patients and 25 healthy controls were involved in the study. Serum sample collected from the patients by venipuncture were evaluated by Beutler's method. The data obtained were analyzed using the one way ANOVA test. There was a significant difference between the levels of serum glutathione in between oral cancer, oral leukoplakia groups when compared to healthy controls. The levels of serum glutathione were lower in oral cancer when compared to oral leukoplakia but the difference was not statistically significant. The results suggest that serum glutathione level estimation could be used to determine the risk of oral cancer.
\end{abstract}

Keywords: serum, glutathione, oral cancer, leukoplakia

\section{Introduction}

Oral cancer (OC) is the most common cancer in South Asia and accounts for $40 \%$ of all malignancies in the Indian Subcontinent [1]. Several oral lesions such as leukoplakia (OL), erythroplakia and lichen planus carry an increased risk for malignant transformation to $\mathrm{OC}$ in the oral cavity [2]. Smoking and alcohol intake are the best defined and extensively researched risk factors for OC [3]. DNA damage, occurring as the result of detrimental effects of certain agents, in large part by the products of oxidative metabolism and in particular by reactive oxygen species (ROS), are probably the most potential spontaneous mutagenic events [4]. The scavenging of the ROS in physiological system such as blood and tissues is carried out by enzymatic and non-enzymatic antioxidants [5]. The enzymatic antioxidant includes superoxide dismutase, catalase, glutathione peroxidase. The nonenzymatic anti-oxidants include lipid soluble vitamins, vitamin $\mathrm{E}$, vitamin $\mathrm{A}$, water soluble vitamin $\mathrm{C}$ and glutathione [5].

Glutathione (GSH) acts as both, a nucleophile and a reductant, and can therefore react with electrophilic or oxidizing species before the latter interact with more critical cellular constituents such as nucleic acids and proteins [6]. Glutathione directly scavenges free radicals, and also serves as a substrate for glutathione peroxidases and glutathione S-transferases during the detoxification of
ROS $[7,8]$. Recently studies have been carried out on glutathione levels in patients with diabetes, dental caries and head and neck squamous cell carcinoma $[3,9,10]$. The aim of our study was to evaluate the levels of serum glutathione in oral leukoplakia and oral squamous cell carcinoma patients.

\section{Methods}

The study involved 75 subjects with age range of 20 to 65 years reporting to the Department of Oral Medicine and Radiology. Twenty-five clinically diagnosed and histopathologically confirmed cases of oral leukoplakia formed the first group (OL). Twenty-five histopathologically confirmed of oral cancer (OC) cases were enrolled into the second group. Twenty-five age and sex matched healthy controls formed the third group (HC). Each of the study groups had five female subjects. Patients with diabetes mellitus and patients with history of previous malignancy were also excluded from the study. $5 \mathrm{ml}$ of venous blood was collected from the antecubital vein by venipuncture. Serum GSH levels, were determined by the method of Beutler [11]. 100 $\mu \mathrm{L}$ of filtered serum was diluted with $1 \mathrm{~mL}$ of distilled water. $500 \mu \mathrm{L}$ of the diluted serum was taken and to this $2 \mathrm{~mL}$ of phosphate solution and $250 \mu \mathrm{L}$ of DTNB [5,5-Dithiobis (2 nitrobenzoic acid)] reagent were added. Simultaneously (use capital letter) a blank was maintained containing $200 \mu \mathrm{L}$ of distilled water, $300 \mu \mathrm{L}$ of precipitating solution, 
$2 \mathrm{~mL}$ of phosphate solution and $250 \mu \mathrm{L}$ of DTNB. The intensity of yellow colour formed was sphectrophotometrically read at $412 \mathrm{~nm}$ against blank using "Cystronics 106"(wavelength 340-960nm). The optical densities obtained were plotted against the standard graph. The concentration of glutathione was calculated graphically and multiplied with respective dilution factors and the total glutathione in the sample was expressed as mmol/L. The data obtained were subjected to statististical analysis using SPSS version 17 software. One-way ANOVA was used to compare the data among the groups and the differences were considered statiscally significant if $\mathrm{P}$ values were 0.05 or less.

\section{Results}

The mean serum glutathione in group OL was $01.04 \pm$ $0.22 \mathrm{mmol} / \mathrm{L}$. Whereas in group OC the mean serum glutathione level was $0.94 \pm 0.27 \mathrm{mmol} / \mathrm{L}$. The mean serum glutathione level of the group $\mathrm{HC}$ was $1.88 \pm$ $0.36 \mathrm{mmol} / \mathrm{L}$. The mean serum glutathione levels of the male subjects in study groups OL, OC and HC were 0.94 $\pm \quad 0.28 \mathrm{mmol} / \mathrm{L}, \quad 0.72 \pm 0.28 \mathrm{mmol} / \mathrm{L}$ and $1.97 \pm$ $0.17 \mathrm{mmol} / \mathrm{L}$ respectively (Figure 1 ). Whereas the mean serum glutathione levels of the female subjects in study groups OL, OC and $\mathrm{HC}$ were $0.91 \pm 0.07 \mathrm{mmol} / \mathrm{L}, 0.86 \pm$ $0.19 \mathrm{mmol} / \mathrm{L}$ and $1.74 \pm 0.27 \mathrm{mmol} / \mathrm{L}$ respectively (Figure $2)$. The serum glutathione levels of female subjects were lower than male subjects but not statistically significant. When the mean serum glutathione level of group OL was compared to group $\mathrm{HC}$ a statistically significant difference $(\mathrm{p}=0.001)$ was observed. The mean serum glutathione level of group OC was higher than group OL but the difference was not statistically significant $(p=0.1)$. The mean serum glutathione level of OC group was significantly lower $(\mathrm{p}=0.001)$ than the HC group (Figure 3).

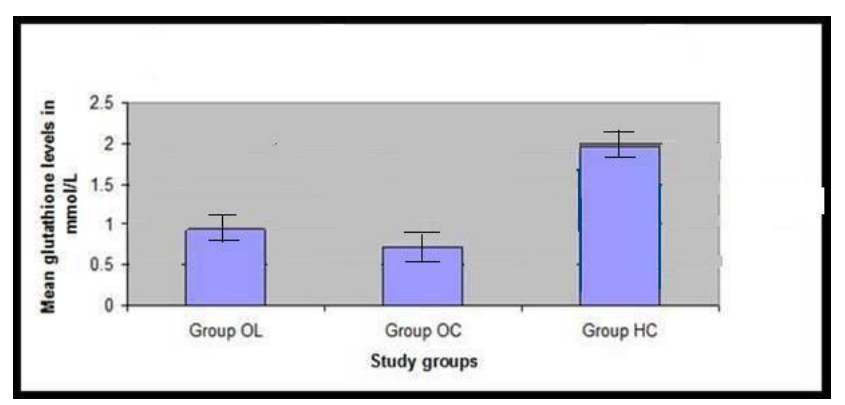

Figure 1. Mean serum glutathione levels in male study subjects

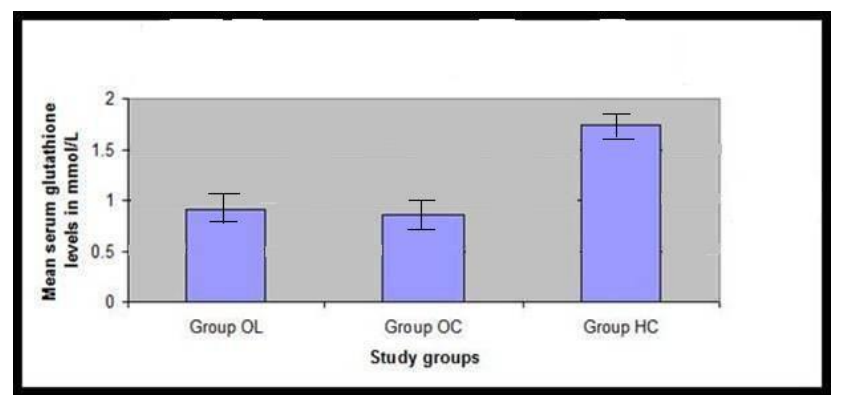

Figure 2. Mean serum glutathione levels in female study subjects

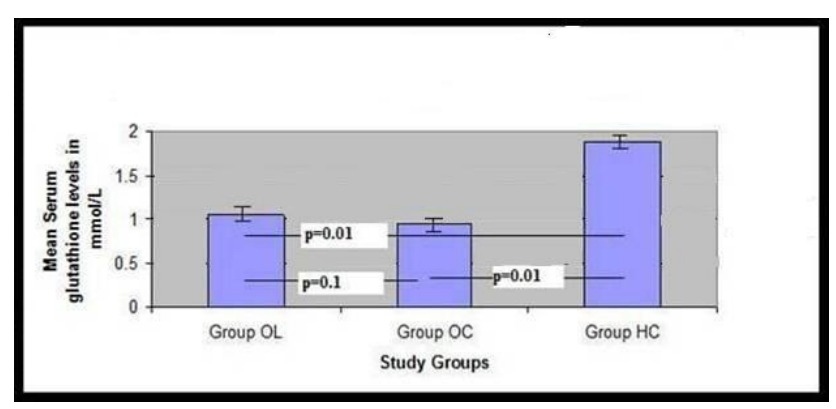

Figure 3. Intercomparison of mean serum glutathione levels in the study groups

\section{Discussion}

Glutathione (GSH) is a major intracellular antioxidant and hence plays a major role in cancer prevention [12]. GSH acts as first line of defense against oxidative stress [13]. Few studies have shown a reduced occurrence of polycyclic aromatic hydrocarbon induced oral cancer in experimental animals fed with diet rich in glutathione $[14,15]$. GSH detoxifies carcinogens and also regulates immune system by mitogenic response and lymphocytic proliferation $[16,17]$. Several serum studies have revealed decrease in the levels of plasma GSH levels in oral cancer [18]. In one Indian study the levels of plasma glutathione consistently reduced in the advanced stages of oral cancer when compared to initial stages [19]. Utilization of the glutathione by tumor tissues or by excessive oxidation in circulation were the probable reason for the depletion of gluthione in plasma [19]. Recently few studies have been carried out on salivary glutathione levels in smokers and in patients with dental caries and oral cancer $[3,5,20]$. These studies showed alterations in glutathione levels in study groups when compared to controls. In our study we evaluated serum glutathione in oral cancer and precancer patients. We found reduced glutathione levels in both oral cancer and precancer study groups. This depletion could be due to an imbalance in the free-radical and antioxidant homeostasis in the body fluids that occurs during carcinogenesis. Although statistically insignificant, the serum glutathione levels in oral cancer patients were higher than patients with leukoplakia. The results obtained from this study suggests that the altered levels of serum glutathione could be used as an ancillary screening tool for individuals with risk of oral cancer.

\section{References}

[1] Parkin DM, Pisani P, Ferlay J. Estimates of worldwide incidence of 25 major cancers in 1990. Int J Cancer. 1999; 80:827-841.

[2] Hirshberg A, Calderon S, Kaplan I. Update review on prevention and early diagnosis in oral cancer. Refuat Hapeh Vehashinayim. 2002;19(3):38-48, 89.

[3] Almadori G, Bussu F, Galli J, Limongelli A, Persichilli S, Zappacosta B, Angelo Minucci A, Paludetti G, Giardina B. Salivary glutathione and uric acid levels in patients with head and neck squamous cell carcinoma. Head Neck 29: 648-654, 2007.

[4] Marnett LJ. Oxyradicals and DNA damage. Carcinogenesis 2000;21:361-370.

[5] Bathi RJ, Rao R, Muthalik. GST null phenotype and antioxidants; risk indicators for oral precancer and cancer. Indian J Dent Res; 20(3): 298-302. 
[6] Hayes JD, McLellan LI. Glutathione and glutathione-dependent enzymes represent a co-ordinately regulated defence against oxidative stress. Free Radic Res 1999;31 :273-300.

[7] Pompella A, Visvikis A, Paolicchi A, De Tata V, Casini AF. The changing faces of glutathione, a cellular protagonist. Biochem Pharmacol 2003;66:1499-1503.

[8] Pastore A, Federici G, Bertini E, Piemonte F. Analysis of glutathione: implication in redox and detoxification. Clin Chim Acta 2003;333:19-39.

[9] Öztürk LK, Furuncuoglu H, Atala MH, Uluköylü O, Akyüz S Yarat A. Association between dental-oral health in young adults and salivary glutathione,lipid peroxidation and sialic acid levels and carbonic anhydrase activity Braz J Med Biol Res, 2008; 41: 956-95.

[10] Gümüş P, Buduneli N, Çetinkalp S, Hawkins SI, Renaud D, Kinane DF, Scott DA Salivary Antioxidants in Patients With Type 1 or 2 Diabetes and Inflammatory Periodontal Disease: A CaseControl Study. J Periodontol, 2009; 80(9):1440-1446.

[11] Beutler E. Glutathione in red blood cell metabolism. In: Beutler E (Editor), A manual of biochemical methods. 2nd edn. New York: Grune and Stratton; 1975. p 112-114.

[12] Locigno R, Castronovo V: Reduced glutathione system: role in cancerdevelopment, prevention and treatment (review). Int $\mathrm{J}$ Oncol 2001; 19: 221-236.
[13] Sies H. Glutathione and its role in cellular functions. Free Radic Biol Med 1999; 27: 916-921.

[14] Trickler D, Shklar G, and Schwartz J: Inhibition of oral carcinogenesis by glutathione. Nutr Cancer 1993; 20: 139-144.

[15] Schwartz JL and Shklar G: Glutathione inhibits experimental oral carcinogenesis, p53 expression, and angiogenesis. Nutr Cancer 1996; 26: 229-236.

[16] Hamilos DL and Wedner HJ: The role of glutathione in lymphocyte activation: comparison of inhibitory effects of buthionine sulfoximine and 2-cyclohexene-1 one by nuclear size transformation. J Immunol 1985; 135: 2740-2747.

[17] Wu G, Fang YZ, Yang S, Lupton JR, and Turner ND: Glutathione metabolism and its implications for health. J Nutr 2004; 134: 489492.

[18] Richie JP, Kleinman W, Marina P, Abraham P, Wynder EL, Muscat JE. Blood Iron, Glutathione, and Micronutrient Levels and the Risk of Oral Cancer. Nutr Cancer 2008; 60: 474-482.

[19] Manoharan S, Kolanjiappan K, Suresh K, Panjamurthy K. Lipid peroxidation \& antioxidants status in patients with oral squamous cell carcinoma. Indian J Med Res 2005; 122: 529-534.

[20] Sathishkumar T, Shanmugam S, Rameshkumar S, Rajavelan G, Haridoss. Characterization of Salivary Glutathione reductase in Normal Individuals and its Implications on Smokers. Researcher 2010; $2: 74-81$. 